\title{
XLIV. On a new polarizing prism
}

\section{Professor Silvanus P. Thompson B.A. D.Sc.}

To cite this article: Professor Silvanus P. Thompson B.A. D.Sc. (1881) XLIV. On a new polarizing prism , Philosophical Magazine Series 5, 12:76, 349-351, DOI: 10.1080/14786448108627118

To link to this article: http://dx.doi.org/10.1080/14786448108627118

曲 Published online: 28 Apr 2009.

Submit your article to this journal

Џll Article views: 7

Q View related articles $₫$ 
originally were each bisected by the axis of $y$, have then come to occupy the two remaining opposite quadrants. Thus the one set of curves of constant induction merges into the other, and the forms of both sets, which may be described as ovals, depend upon the angle between the axes of the primary and secondary coils.

We see, then, that the second set of curves, although found experimentally, are not entirely independent of the first set, and that being positive and negative in alternate quadrants, they have no corresponding surfaces of revolution, that the only curves of constant induction which have corresponding surfaces of revolution are those which are obtained when the axes of the primary and secondary coils are parallel, and that all curves of constant induction which are due to the coils when their axes make any other angle with each other are merely modified forms of them.

The arrangement of apparatus employed in this investigation, namely two similar coils in the primary and two other similar coils in the secondary circuit, was employed by Dove in his researches, and was called by him the "Differential Inductor" (Annales de Chimie et de Physique, tome iv. 1842).

The same arrangement was employed by Felici, a short account of whose researches is given in Maxwell's 'Electricity and Magnetism,' vol. ii. pp. 169-172.

In conclusion, my special thanks are due to Prof. G. C. Foster, for the general interest which he has taken in this subject, and for many important suggestions made during the progress of the investigation.

XLIV. On a New Polarizing Prism.

$B y$ Professor Silvanus P. Thompson, B.A., D.Se.*

1. NEITHER the polarizing prism of Nicol nor that of 1 Foucault can be regarded as perfect. The latter especially has so small an angular aperture available, as to be very inconvenient for any but narrow beams of parallel light. The author has sought to improve upon the existing fornis of polarizing prism; and his investigations into the cause of their defects have led him to produce prisms having a considerably wider effective angular aperture.

2. In the text-books it is usual to tell students that in the Nicol prism the ordinary ray is suppressed by total reflexion because the ordinary index of refraction is greater than that

- Communicated by the Author, having been read before Section A of the British Association, September 7, $188 \hat{1}$. 
of balsam, and that the extraordinary ray is transmitted because the extraordinary index of refraction is less than that of balsam. Neither of these statements is completely true. All that its inventor claimed for the Nicol prism*, and all that it actually performs, is as follows:-The critical angle of total reflexion being different for ordinary and extraordinary rays, the ordinary ray is totally reflected and thrown out of the field at an incidence at which the extraordinary ray is still transmitted, the available field of polarized light being the region between the points where the extraordinary ray itself vanishes by total reflexion and the ordinary ray enters by lack of total reflexion. The former limit is in all ordinary Nicol prisms marked by a broad blue iris or band of colour; the latter is delimited by a curved band at the opposite side of the field, in which, amidst a prevailing line of red and orange, a system of interference-bands can be seen. The existence of these interference-fringes was examined by the author in 1877, in a paper which appeared in the Proceedings of the Physical Society of London, vol. ii. p. 157. In the Foucault prism a similar limitation of the field occurs, interference-fringes being visible at both limits.

3. The refractive index of balsam for light of mean refrangibility may be taken as 1.54 , that of the ordinary ray in calc-spar as $1 \cdot 66$, that of the extraordinary ray as $1 \cdot 487$. "The reciprocals of these are very nearly in the respective proportions of $65,67,60$. The extraordinary index, however, is 1.487 only for rays at right angles to the crystallographic axis, having there a minimum, and increasing up to 1.66 for rays whose direction coincides with that of the axis. The ellipsoidal.wave-surface of the sheet of extraordinary waves lies partly without and partly within the spherical wave-surface for canada balsam, while the spherical wave-surface of the sheet of ordinary waves lies wholly within. Hence total reflexion may occur for the extraordinary as well as for the ordinary rays; but of the extraordinary rays only those can suffer total reflexion which are situated in such a direction with respect to the optic axis that their corresponding portion of the ellipsoidal wave-surface lies within the spherical wave-surface for balsam. As the Nicol prism is usually constructed, this limit of possible extraordinary total reflexion occurs for rays (in a principal plane of section) inclined at about $10^{\circ}$ to the balsam film, giving rise to the limit of the polarized field marked off by the blue iris before mentioned.

* See Edinburgh New Philosophical Journal, 1828, p. 23, W. Nicol, "On a Method of so far increasing the Divergency of the two Rays in Calcareous Spar that only one Image may be seen at a time." 
4. The author has succeeded in widening the available field of polarized light by constructing polarizing prisms in which this blue iris, and the total reflexion of the extraordinary ray which produces it, are got rid of. This can be done by cutting the crystal so that (1) the balsam film lies in a principal plane of section, and (2) the crystallographic axis is at right angles to the axis of the prism.

The result of this mode of orientation of the axis and film is to gain $9^{\circ}$ of angular aperture at this side of the "field," supposing the angles respectively made by the film and by the terminal planes with the axis of the prism to be the same as in the Nicol prism.

It is possible to produce a further increase in width of available aperture at the other side of the field by reflecting back the ordinary ray more than in the Nicol prism by making the terminal faces more oblique; but there is then more loss of light by reflexion at the surfaces.

5 . Beside the advantage of a wider angular aperture, this new form of polarizing prism has the advantage of producing a field in which the rectilinear polarization approximates more uniformly and symmetrically to a polarization in one plane than is the case in the ordinary Nicol. There is, however, more waste in cutting the spar, with proportionate increase in cost.

XLV. Phenomena of Binaural Audition.-Part III. $B y$ Professor Silvanus P. Thompson, B.A., D.Se.*

1. TN the author's papers of 1877 and 1878 he stated that, when two separate simple tones reach the ears without previously mingling, the difference-tone, or grave harmonic, is not heard, though beats are if the tones are within beatingdistance. The latter statement referred to the beats of imperfectly-tuned unisons, which was the only case of primary beats examined at the time $\dagger$.

* This paper, read before Section A of the British Association at York, continues the researches communicated to the British Association by the Author in 1877 and 1878, and printed in this Magazine. See p. 274, Oct. 1877 , and p. 383 , Nov. 1878.

+ This phenomenon of subjective interference, which was announced in the author's paper of 1877, and further discussed in his paper of 1878 , was independently announced on Nov. 28, 1877, by Professor Graham Bell as having been discovered by himself and Sir W. Thomson (subsequently to the publication of the author's first paper). The phenomenon was also known in 1874 to Mach, who mentions it at the end of a paper on the Functions of the Pinnæe of the Ears (published in the Archiv fitr Ohrenheilkunde), and ascribes it to a conduction of the sound through the mass of the skull. 